\title{
Efficiency of Stick-held Cast Nets in the Capture of Indian Squid in the Gulf of Thailand ${ }^{\dagger}$
}

\author{
Mala Supongpan*1 and Masatosi Sinoda*2 \\ *1Bangkok Marine Fisheries Development Center, 89/1 Charoen Krung 58, Yanawa, \\ Bangkok 10120, Thailand \\ ${ }^{*}$ Kyoto Institute of Oceanic and Fishery Science, Odashukuno, Miyazu, \\ Kyoto 626, Japan
}

(Received December 20, 1994)

\begin{abstract}
A series of light-luring fishing trials, 84 hauls for 20 days, were conducted by a commercial vessel off the west coast in the Gulf of Thailand using a stick-held cast net from March 1991-February 1992. The mean catches were approximately constant, about $16 \mathrm{~kg} / \mathrm{haul}$, in a range of light-luring times from $1.5 \mathrm{~h}$ to $5.5 \mathrm{~h}$. When haul by haul catches decreased, it was clearly shown that the larger squid in a shoal were captured preferentially. However, there did not appear to be any considerable changes in the size structures of squid caught by successive hauls, when haul by haul catches increased or decreased. The number of squid aggregated into the lit area was estimated to be about 1,000-3,000. The efficiency of the cast net may be a function of the number of squid, or in other words, a low catch efficiency might be caused mainly by dispersion of shoals at low density or by gear saturation at high density.
\end{abstract}

Key words: Indian squid, catchability, stick-held cast net, squid shoal, the Gulf of Thailand, Loligo duvauceli

A variety of small fish are simultaneously caught by stick-held cast nets, with a higher proportion of commercially important Indian squid Loligo duvauceli in the Gulf of Thailand. It is suggested that the squid strongly aggregate to the light-luring area to seize prey where fish form dense swarms. During the night between sunset and sunrise, squid shoals are captured by a successive haul of cast nets. As reported in a previous paper, ${ }^{1)}$ the trend of successive catches with time can be simply classified into three types. For two of these, it is suggested that other squid are recruited steadily into the catchable shoal from the surrounding area, so that the catch increases gradually or exceptionally with time in accordance with the prey aggregate. For the other type, the catch decreases by repeated hauling up to the final haul, as is observed in some specific fishing grounds in the Gulf. It is probable that increasing or decreasing trends of successive catches may be due mainly to the appearance of the prey" and the changes of squid size structure in a shoal may be caused by recruitment and dispersals. In order to determine the change of size structure with time, a commercial fishing vessel operating a stick-held cast net sampled the squid from catches by haul and recorded the amount of squid caught in the sea off Chumporn province on the west coast in the Gulf of Thailand.

Within a total of 20 fishing days, since successive catches decreased, the present study investigated the changes in the size structure of the squid with decreases in catch with time and the efficiency of the cast net based on Leslie's model. ${ }^{2)}$ In this study, the squid that aggregate in the lit area around a vessel are treated as a shoal that represents the elementary population ${ }^{3)}$ of the Indian squid in view of fisheries' biological significance. ${ }^{4)}$

\section{Materials and Methods}

The catch data used in this study were collected by a commercial vessel (length $12 \mathrm{~m}, 185$ H.P. engine) fishing in the sea off Chumpon province (depths 20-30 m). From March 1991 to February 1992, the vessel recorded a series of squid fishings, as well as the catch in weight and lightluring time, and randomly sampled the squid from haul by haul catches. Because of the effects of the NE monsoon, catch records and squid samplings for November-December 1991 were not made. Throughout the period of 10 months, 84 hauls using stick-held cast nets were conducted, with four hauls per day on average.

The catch was recorded in terms of the weight of mixed squid of sexes, and the time intervals between lighting on and off to attract the squid recorded in minutes were grouped into $30 \mathrm{~min}$ classes. The squids were sampled haul by haul to see the size structure of squids appearing in the catch. The mantle lengths (ML: length of mantle from most anterior point on the dorsal side to the posterior body tip) of fresh samples were measured to the nearest millimeter and grouped into $1 \mathrm{~cm}$ length classes.

To estimate the efficiency of the cast nets, in other words the ratio of CPUE (individual numbers of squid per haul) to the number of squid in a shoal, and the initial number of squid in a shoal at the first haul, Leslie's model ${ }^{2)}$ was applied. When successive catches of squid in a night showed a decreasing tendency haul by haul, it was assumed that the catches decreased as the shoal became depleted, and the amount of decrease reflected the extent of depletion by

\footnotetext{
${ }^{\dagger}$ Contribution No. 98 from the Kyoto Inst. Ocea. Fish. Sci.
} 
successive exploitations by the cast net with a given efficiency. In this analysis of catch data, the squid catch recorded in weight by haul was converted into individual numbers, on the basis of a mixed ML composition of the two sexes and the ML-weight relationships." The cast net was conical in shape as shown in Fig. 1, and the lengths of the net and net-mouth circumference were $18 \mathrm{~m}$ and $42 \mathrm{~m}$, respectively. The mouth of the net consisted of large chain pieces or lead of $70 \mathrm{~kg}$ total weight. The purse line $(100-120 \mathrm{~m}$ in length) was passed through small rings attached along the weighted ropes. Incandescent bulbs of $500 \mathrm{~W}$ each were used as luring lamps to attract squids and 26 bulbs were fixed to six bamboo poles (lengths of $3.5-4.0 \mathrm{~m}$ ). Two spotlight bulbs (red and white) midship on the starboard side were added in order to effectively concentrate the squid to the catchable area just under the cast net.

On reaching the fishing ground, the vessel drifted using a drift net (about 200-400 $\mathrm{m}$ in length, $10-14 \mathrm{~m}$ deep) ${ }^{6}$ ) as a sea-anchor. After sunset, as the crew located the squid shoals from experience, all the lamps in the rigging of the vessel were switched on and the net was set ready for release. When the squid aggregated well around the vessel, all the lamps except the ones midship on the starboard side were switched off. Then, the lamps were gradually dimmed, and the squid rushed towards the area lit by the two spotlights, seemingly equal to the size of the area (140 $\mathrm{m}^{2}$ ) covered by the cast net. During this time, the lighting intensity of the white spotlight was further reduced and then switched off while the red spotlight remained on. The squid shoal came up to the surface of the water enough to be easily covered with the cast net. The cast net (Fig. 1(I))

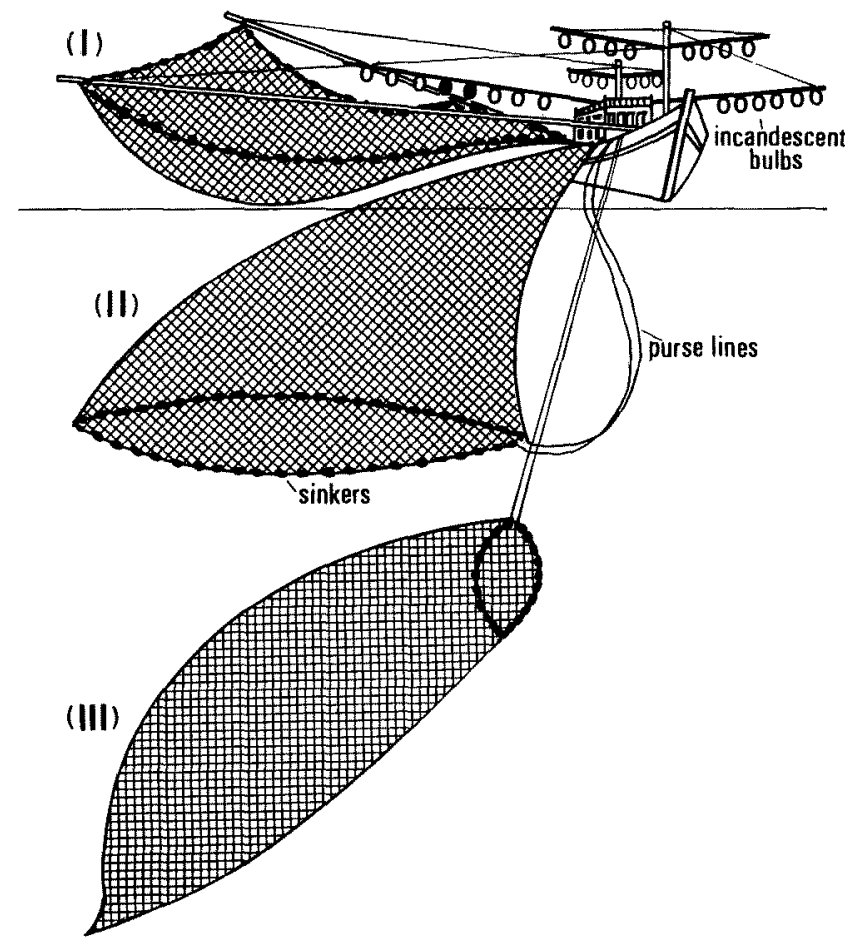

Fig. 1. General arrangement of the stick-held cast net in operation. (I) The cast net set on two bamboo outriggers, (II) the net cast for a shoal of squid aggregated in an area spotlit by one or two bulbs (closed), (III) the mouth of the cast net pursed by lines. set on bamboo outriggers was cast off to cover the squid shoal (Fig. 1(II)), and the net mouth was pursed by the lines (Fig. 1(III)). This operation was repeated as many times as possible until the sun or moon rose, that is, the number of fishing operations, or the light-luring time interval, are dependent on the sea and lunar conditions and the amount of squid which aggregate.

\section{Results and Discussion}

\section{Light-luring Time Required for Aggregating Squid and Catch by Haul}

The light luring times required are from locating a squid shoal to the first haul, and between two successive hauls. The number of hauls per night varied daily, ranging from $1-2$ hauls (5\% of 84 hauls), 3-4 hauls (55\%) and 5-6 hauls (40\%). The shortest time was $30 \mathrm{~min}$ and the longest $7.5 \mathrm{~h}$, but mostly the time required was $1.0-3.5 \mathrm{~h}(67 \%$ of 84 hauls) and sometimes rather longer $4.0-5.5 \mathrm{~h}(21 \%)$. As times of less than $1.5 \mathrm{~h}$ and longer than $5.5 \mathrm{~h}$ were due to unsuitable fishing conditions such as rough sea or gear breakdown, it seems reasonable to consider that the luring time of a haul for aggregating squid was normally 1.5-5.5 h. Incidentally, the fishermen usually operate the cast nets at 3.0-3.5 h intervals whenever possible. In the later analysis, therefore, the catch records were limited to those with luring times of $1.5-5.5 \mathrm{~h}$.

The mean catches $(\mathrm{kg} / \mathrm{haul})$ by luring times are shown in Fig. 2, grouped into $30 \mathrm{~min}$ intervals for luring times from $1.0-4.0 \mathrm{~h}$, and into $1 \mathrm{~h}$ intervals from $4.5-5.5 \mathrm{~h}$ because of the small frequency of hauls (10\% of 84 hauls). The mean catches were approximately constant, about 16

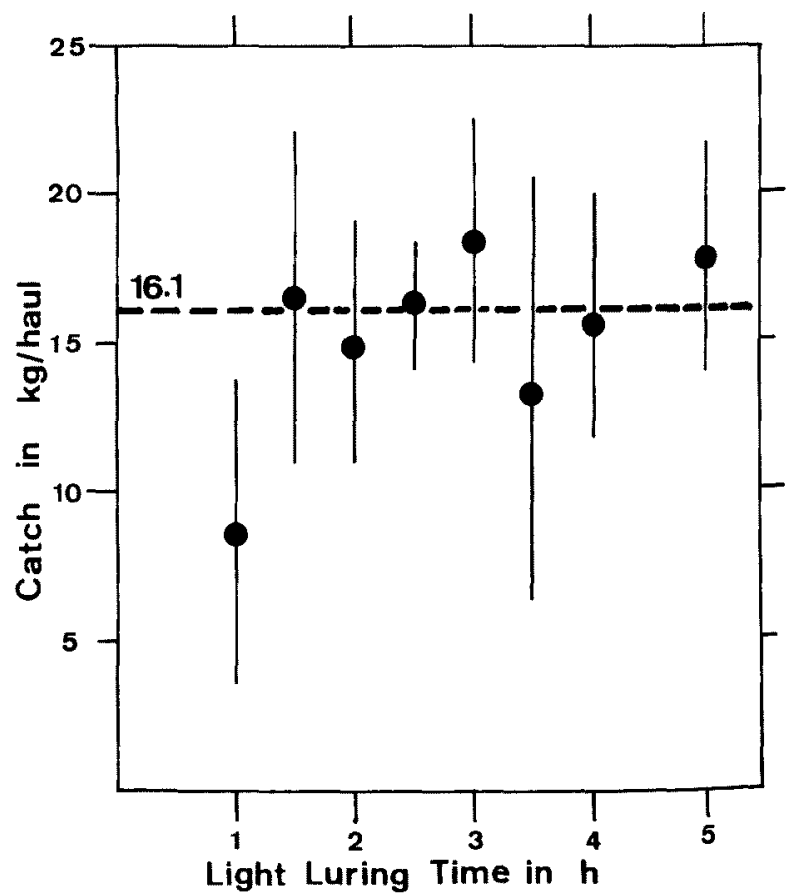

Fig. 2. Mean catches (kg/haul) of Indian squid grouped into $30 \mathrm{~min}$ intervals of light-luring time from 1 to $4 \mathrm{~h}$, and $1 \mathrm{~h}$ intervals from 4.5 to $5.5 \mathrm{~h}$.

The catches are approximately constant, about $16 \mathrm{~kg} / \mathrm{haul}$, ranging from 1 to $5.5 \mathrm{~h}$ of light-luring time. 
$\mathrm{kg} / \mathrm{haul}$, in the range of luring times from $1.5 \mathrm{~h}$ to $5.5 \mathrm{~h}$. Thus from a practical viewpoint, one important suggestion is that since a cast net fishery is sustained by substantial squid shoals, the value of the mean catch is effectively an index of the unit size of squid shoal aggregated into the area lit by the vessel.

Changes of Catch and Size Structure by Successive Haul As it is likely that the squid shoals with a variety of ML recruit into a lit area and/or disperse from the area, the catches each night vary haul by haul. On the other hand, the efficiency of the cast net might be compoundly affected by the amount of squid aggregated, and the sea and lunar conditions. Typical examples of successive catch trends (Types A-D in Fig. 3) were as follows.

Type A Catch increased gradually haul by haul, as observed on 20 March 1991.

Type B Catch was approximately constant throughout the night, as observed on 22 March 1991.

Type C Catch decreased then increased markedly during the course of successive hauls, as observed on 10 April 1991.

Type D Catch decreased haul by haul, as observed on 6 July 1991.

The size frequency distributions for each type show interactive changes in the squid size (ML) with each succes-

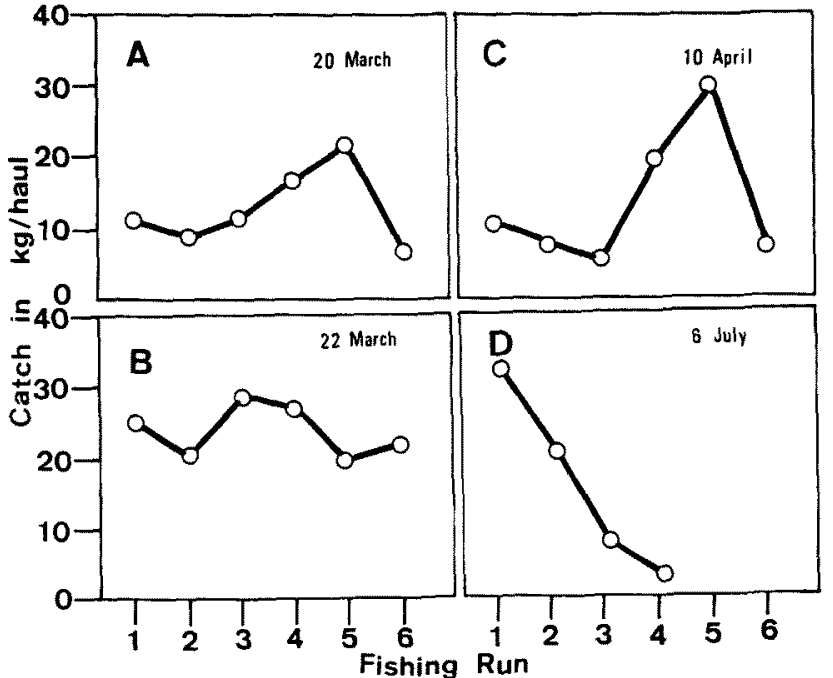

Fig. 3. Four typical trends (A-D) of catches ( $\mathrm{kg} /$ haul) of Indian squid by successive haul.

sive haul (Fig. 4), especially in Types C and D. As shown in Fig. 4, the mean ML decreased with successive haul, from $10.6 \mathrm{~cm}$ to $9.0 \mathrm{~cm}$ in Type $\mathrm{C}$ and from $10.7 \mathrm{~cm}$ to 8.6

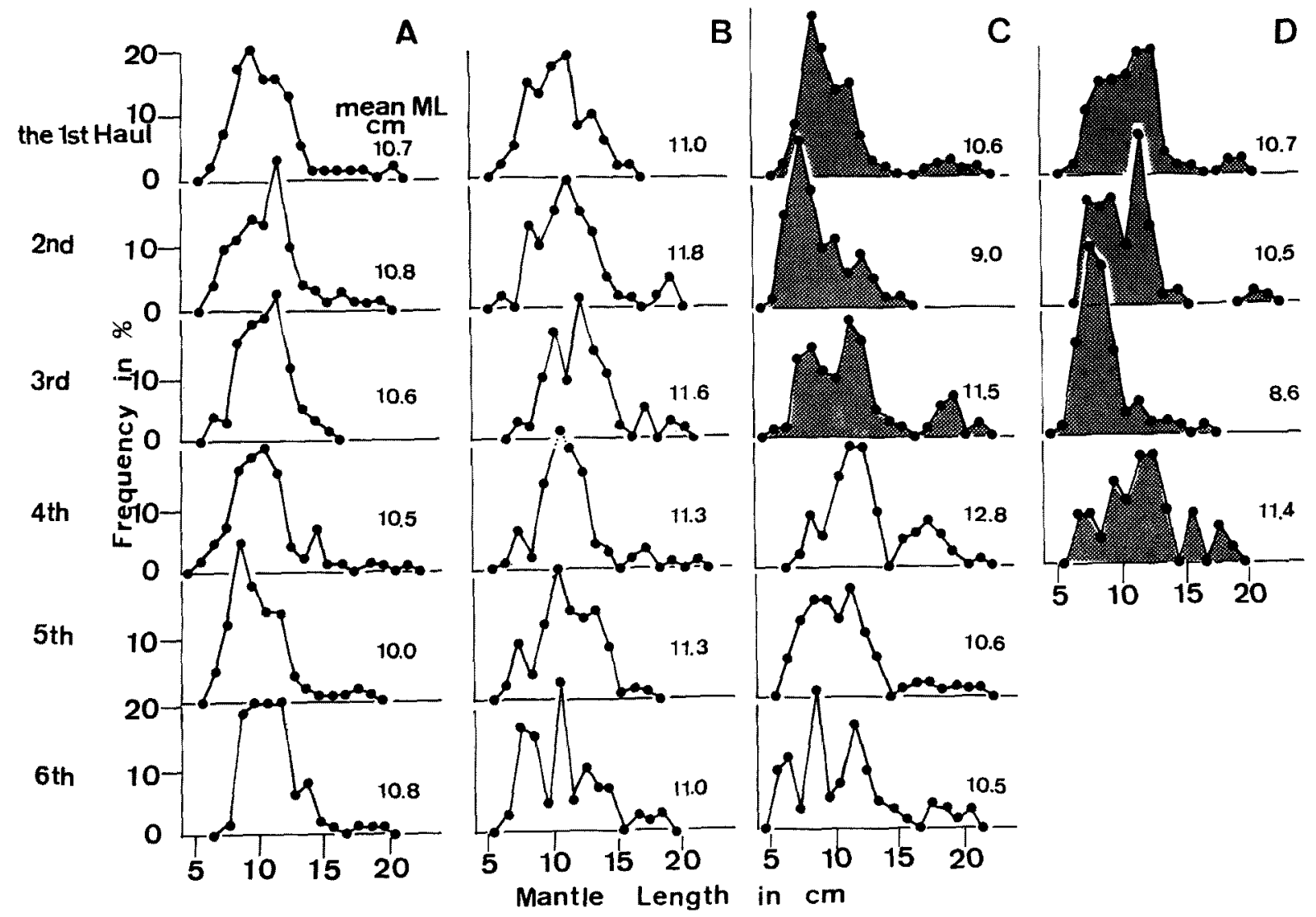

Fig. 4. Size frequency distributions of Indian squid caught from the Ist haul to the 6 th haul in Types $A, B$, and $C$ in Fig. 3, and from the 1st haul to the 4th haul in Type D.

Mean mantle lengths of squid in $\mathrm{cm}$ are shown on each right side, and the shaded frequency distributions represent cases of decrease in catch haul by haul in Types $C$ and $D$. 
$\mathrm{cm}$ in Type D. Thus, probably due to mixture with rather large size squid (larger than about $10 \mathrm{~cm}$ ML), size frequency distributions in the $3 \mathrm{rd}$ haul in Type $C$ and the 4th haul in Type D show larger ML than those by previous hauls. In Types $\mathrm{A}$ and $\mathrm{B}$, however, there did not appear to be any considerable differences $(0.8 \mathrm{~cm}$ in mean $\mathrm{ML})$ through the 1st-6th hauls. Therefore, it seemed that the size frequency distributions in Types $C$ and $D$ were affected by exploitation of the cast net without any substantial recruitments, though there is no direct evidence.

At the 2nd haul in Type $C$ and the 3rd haul in Type D, the percentage occurrences of large groups (larger than 10 $\mathrm{cm}$ ML) of the squid decreased suddenly. This suggests that larger squid might preferentially occupy the lit area and be captured, due to the appearance of prey such as the Indian mackerel Rastrelliger kanagurta. ${ }^{1)}$ Thus, a higher incidence of smaller squid (smaller than $10 \mathrm{~cm} \mathrm{ML)} \mathrm{might} \mathrm{be}$ found in the next catch, which may feed primarily on planktonic organisms. ${ }^{7,8)}$

\section{Estimations of Efficiency of Cast Net and Individual Num- bers of Squid in a Shoal}

The same trends as Type D showing that catches decreased successively in two hauls were observed in five days for three hauls and four days for four hauls. In these nine examples (days), it is assumed that the unit of squid shoals remained steadily in the lit area from the first haul to the last. Catches $(\mathrm{kg} / \mathrm{haul})$ were converted into individual numbers of squid, based on the size frequency distribution by haul and the mixed ML-weight relationships of the two sexes. ${ }^{5)}$ In order to verify whether the decline in catch (individual numbers of squid per haul) was due to the effect of the exploitation or not, Leslie's method was applied to catches in the nine examples. As shown in Fig. 5, it is seen that the plots of catches by four successive hauls (four examples) decreased linearly with increasing cumulative catch, and the efficiency of the cast net and initial number of squid in a shoal were estimated. For the five examples showing catch decreases in three successive hauls, the efficiency and the number of squid were obtained using the same method as that in Fig. 5. The efficiency of the cast net, generally defined as catchability " $q$ ",,, 10 ) was estimated at 0.383-0.553 per haul (Fig. 6) from the slope of each of the nine examples. The initial number of squid in a shoal could also be approximated at 1,483-3,052 individuals.

Now, let us consider the characteristics of the value of $q$. It is clear that the value depends on the relationship between the individual number of squid aggregated in the lit area around a vessel and the number of squid encountering the cast net as shown in Fig. 6. If all the squid in the area aggregate into the spot-lit area and encounter the net, the value of $q$ is the exploitation rate per haul, generally in the range of 0 to 1 . According to Boongerd and Chitrapong $^{6}$ and Muntz, ${ }^{11)}$ a squid responds sharply to reductions in light intensity over a few minutes. It seems that the squid mostly aggregate into the spot-lit area, so the value of $q$ might be equal to the exploitation rate per haul, in other words the ratio of CPUE (individual number of squid per haul) to the number of squid in a shoal aggregated into the lit area around a vessel.

In Fig. 6, it is apparent that the plot of $q$ for each initial

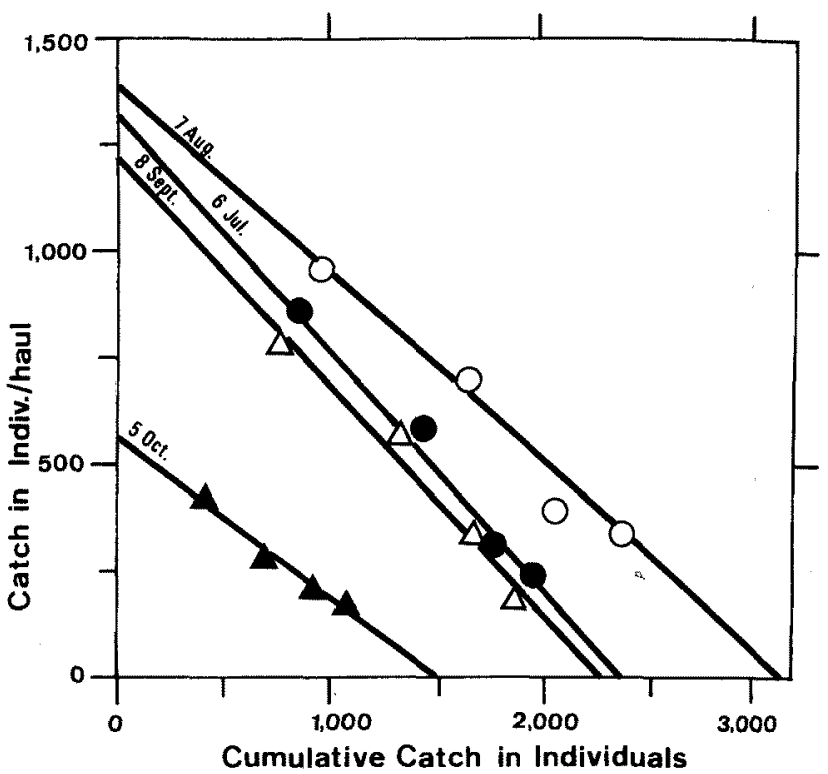

Fig. 5. Four examples of Leslie plots of catches (individuals/haul) of Indian squid by successive hauls.

Catch decreases haul by haul as in Type D in Fig. 3, observed 6 July $(\bullet), 7$ August $(O), 8$ September $(\triangle)$ and 5 October $(\Delta)$.

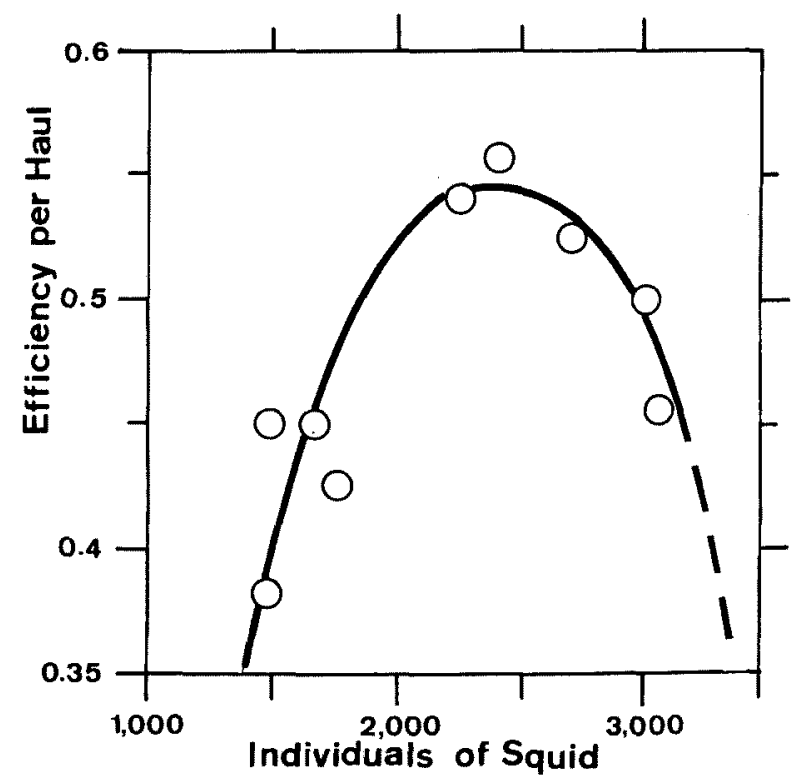

Fig. 6. Plots of $q$ (efficiency per haul) for each initial number of squid in a shoal aggregated into the lit area.

Parabola-like curves were fitted by eye using a French curve, and nine plots represent the estimated values by Leslie's method in the cases in which catches decreased successively in two hauls, five examples (days) for three hauls and four examples for four hauls.

number of squid provides a reliable parabola with a smooth curve opening downwards with a well-defined higher value of $q, 0.55$ per haul. Around the value of $q$, the individual number of squid ranges from 2,250 to 2,500 on the abscissa. Assuming that the spot-lit area is nearly equal to the opening mouth of the cast net, $140 \mathrm{~m}^{2}$, the highest catch per haul may be given as $16.1-17.9$ squid per 
$\mathrm{m}^{2}$.

The low efficiency of the cast net may be caused mainly by dispersion of the squid shoal from the spot-lit area, which occurs in the range between 10.7-12.9 squid per $\mathrm{m}^{2}$ (1,500-1,800 squid), and by gear saturation in the case of more than 21.4 squid per $\mathrm{m}^{2}$ (3,000 squid). It seems that gear saturation may be caused not by squid but by enmeshed fish. ${ }^{6}$ This implies that mid-density squid between 12.8 to 21.4 squid per $\mathrm{m}^{2}$ have mutual swarming interactions, under which condition the cast net operates more effectively. Since, as far as the authors know, very little information is available concerning the efficiency of the stick-held cast net for capturing squid with the aid of a luring light, the results obtained in this study can not be critically discussed here. It is claimed that luring lights help to diminish the number of escapes. The efficiency of the cast net supposedly varies depending on the size of gear and vessel used in the Gulf of Thailand. Therefore, comprehensive material or information on the factors governing the overall efficiency of the cast net fishery using a variety of nets and vessels are desirable.

Acknowledgments The authors wish to express their deep gratitude to Professors Yutaka Natsukari and Tetsushi Senta, Nagasaki University for their guidance. Thanks are also due to Miss Sunee Suvapepan, Director of the Bangkok Marine Fisheries Development Center, Thailand, for her continuous support and encouragement, and to Dr. Akihiko Kuwahara of Kyoto Institute of Oceanic and Fishery Science and Mr. Somporn Boongerd of the Center for their frequent discussions during the course of this work. We are indebted to Professor Fumio Mitani of Fukui Prefectural University, for his kind comments on the manuscript and to Miss Karuna Kongmuag of the Center for her help with collection of data.

\section{References}

1) M. Supongpan, M. Sinoda, and S. Boongerd: Catch analysis of Indian squid Loligo duvauceli by light luring fishing in the Gulf of Thailand. Nippon Suisan Gakkaishi, 58, 439-444 (1992).

2) W. E. Ricker: Computation and interpretation of biological statistics of fish populations. Bull. Fish. Res. Bd. Canada, 191, 149-151 (1975).

3) N. V. Lebedev: Elementary population of fish, Israel Program for Scientific Translation, Jerusalem, 1969, pp. 26-41.

4) Y. Ogawa and T. Nakahara: Structure of elementary population of pelagic fish and its fisheries biological implication. Bull. Japan. Soc. Fish. Ocean., 33, 15-24 (1978).

5) M. Supongpan: Assessment of Indian squid (Loligo duvauceli) and Mitre squid ( $L$. chiensis) in the Gulf of Thailand, in "In contribution of tropical fisheries biology, FAO/DANIDA Follow-up Training Course on Fish Stock Assessment in the Tropics. Manila, Philippines, January-February 1987", FAO/DANIDA, 1988, pp. 24-41.

6) S. Boongerd and S. Chitrapong: Small-scale fishing for squids and related species, in "Work Plan Implementation (Working Paper), 1986/3", ASEAN/UNDP/FAO Regional Small-scale Coastal Fisheries Development Project, Manila, Philippines, 1986, pp. 2-16.

7) R. F. Hixon: Loligo opalescens, in "Cephalopod Life Cycle" (ed. by P.D. Boyle), Vol. 1, Academic Press, London, 1983, pp. 95114.

8) J. B. Messenger: Prey-capture and learning in the cuttlefish, Sepia, in "The Biology of Cephalopods" (ed. by M. Nixon and J. B. Messenger), Symp. Zool. Soc. Lond. No. 38, Academic Press, London, 1977 , pp. $347-376$.

9) J. A. Gulland: Manual of methods for fish stock assessment. Part 1. Fish population analysis. FAO Man. Fish. Sci., 4, 44 (1969).

10) M. J. Sanders and A. J. Morgan: Fishing power, fishing effort, density, fishing intensity and fishing mortality. J. Cons. int. Explor. Mer, 37, 36-40 (1976).

11) W. R. A. Muntz: Pupillary response of cephalopods, in "The Biology of Cephalopods" (ed. by M. Nixon and J. B. Messenger), Symp. Zool. Soc. Lond. No. 38, Academic Press, London, 1977, pp. 277285. 